\title{
AC 2011-2082: ENGAGING K-12 TEACHERS IN TECHNOLOGY TOOLS TO SUPPORT ELECTRONIC AND MOBILE LEARNING THROUGH AN ONLINE PROFESSIONAL DEVELOPMENT COURSE
}

\author{
Meltem Alemdar, Georgia Institute of Technology
}

Dr. Meltem Alemdar is a Research Scientist in the Center for Education Integrating Science, Mathematics, and Computing (CEISMC) at the Georgia Institute of Technology. Dr. Alemdar has experience evaluating programs that fall under the umbrella of educational evaluation, including K-12 educational curricula, after-school programs, and comprehensive school reform initiatives. Across these evaluations, she has used a variety of evaluation methods, ranging from multi-level evaluation plans designed to assess program impact to monitoring plans designed to facilitate program improvement. Dr. Alemdar's leadership evaluation work includes serving as lead evaluator on NASA's electronic Professional Development Network (ePDN), a new initiative dedicated to preparing teachers to engage their students in STEM (science, technology, engineering and mathematics) fields through the use of NASA-developed learning materials and resources. She also serves as the lead evaluator on several NSF funded Noyce Scholarship programs. She has direct experience leading evaluation of STEM programs and has contributed to evaluations of leadership and STEM related innovations.

\section{Tony Docal, Georgia Institute of Technology}

1. Mr. Anthony Docal Anthony Docal has been President of ORBIT Education, Inc. (OEI) a non-profit 501 (c) 3 organization since its founding in 1997. OEI provides Professional Development opportunities in STEM related fields to pre-college educators, as well as student programs.

Anthony Docal has extensive experience in developing and managing STEM programs for the K-12 community. In 1997 he managed the 4-week professional development activity, Summer Teacher Enhancement Program (STEP) for the Kennedy Space Center Education Office. He has developed multidisciplinary curriculum modules for elementary and middle school grades in various areas including Aeronautics and the Underground Railroad.

After coming to CEISMC at Georgia Tech in 1997, Mr. Docal served as Program Director for Kids Interested In Discovering Science (KIDS) Club and student Summer Enrichment Programs which often included a professional development component for educators involved in those activities.

Mr. Docal has been involved in numerous NASA sponsored activities, including Director of the NASA Educators Resource Center in Georgia which he established in 1992 at Southern Polytechnic State University; Regional Director for the NASA Space Science Student Involvement Program (SSIP) and Co-PI the final year of the NASA Student Involvement Program (NSIP); faculty coordinator for the NASA Summer High School Apprenticeship Research Program (SHARP); consultant to the NASA Office of Space Science Broker/Facilitator institutions at the College of Charleston (SERCH) and the Center for Educational Technologies, Wheeling Jesuit University, (MARSSB). Mr. Docal has supported educator workshops at Kennedy Space Center and the Pre-Service Institute at Langley Research Center. Mr. Docal has been an affiliate member of the NASA sponsored Georgia Space Grant Consortium since 1992 and OEI has been an affiliate institution member since its establishment in 1997.

Currently Mr. Docal is Co-PI on the NASA electronic Professional Development Network (ePDN) a program that provides on-line courses for educators focused on STEM and NASA themes and supports teacher training programs at Kennedy Space Center through a partnership with NSTA and the GE Foundation. 


\title{
Engaging K-12 Teachers in Technology Tools to Support Electronic and Mobile Learning Through an Online Professional Development Course
}

\begin{abstract}
In 2009, NASA awarded Georgia Institute of Technology a contract to develop online professional development (PD) courses for STEM teachers. The Technology Integration Certificate consists of four courses designed to help teachers become more comfortable with technology tools and integrate them in their classrooms. Among the courses within the Technology Integration Certificate, the Engage and Educate - Podcasts In The Classroom course provides participants with examples of how podcasts can be integrated in classroom lessons to engage students in STEM disciplines. During the course, the pros and cons of podcasts are examined and participants are introduced to the tools and techniques for creating podcasts. In this study, we described our online courses and their impact on teachers' professional development. In addition, upon completion of the podcast course, we investigated teachers use of podcast and explored how podcasts were used in the classroom setting. The principle research method employed in this study is to develop aggregate narratives. The narratives describe the effectiveness of the podcast course from the perspective of each course participant.
\end{abstract}

\section{Introduction}

Technology integration into the classroom has been highly encouraged by national and state standards set forth by stake holders. Professional development for teachers in the area of technology integration should evolve from the 2 hour "this is the technology and here is how to use it" workshop to a sustainable model from which teachers can "systemically change instruction" ${ }^{1}$. Research showed that the lack of professional development for K-12 teachers represents a very significant barrier for the use of technology in the classroom. The majority of teachers (85\%) now report feeling "somewhat well-prepared" to use technology for classroom instruction (U.S. DOE, 2009), a notable increase since the 2000 report of the National Center for Education Statistics (NCES) in which 53\% of teachers reported feeling somewhat prepared.

With the rapid expansion of access to collaborative technology tools and mobile devices, mobile learning ("m-learning"), has quickly spread into the k-12 environment. While electronic learning ("e-learning") is viewed as electronically supported learning and teaching where a stationary computer and access to the internet are involved, m-learning can occur anywhere at any time and supports a society that is constantly becoming more mobile. Today, teachers can use resources such as podcasts to enhance their lesson plans, provide support outside of the classroom to students and parents, participate in professional development, as well as engage students in the design and production of projects that can be shared through portable technologies such as mp3 players and mobile phones. Podcasts can be downloaded from a number of sources including websites such as iTunes. In addition to downloading podcasts, instructors with a small degree of technological savvy can create their own podcasts using a variety of software. In some cases, students are even creating their own podcasts to demonstrate learning. Podcasts can deliver content in audio and/or video formats at anytime and anyplace without requiring the user to be connected to a computer. 
In 2009, NASA awarded Georgia Tech a contract to develop online professional development (PD) courses for STEM teachers. One of the goals of this project is to support teachers' professional development through an online curriculum designed to enable teachers to learn skills for integrating technology into the classroom. Traditionally, this type of professional learning has been conducted face-to-face in workshops and summer institutes led by school systems, colleges and universities, educational support agencies, and private corporations. However, this model only reaches teachers who are either within commuting distance of the service provider or are willing and able to travel to a remote site for sometimes weeks at a time. Further, this model does not provide follow-up support to the teachers after the workshop. Often, teachers need mentoring, refreshment of the information provided in the workshops, or simply confirmation that they are on the right track in their thoughts on how to use the knowledge they have gained. These limitations and the necessity to minimize travel due to high energy costs and environmental impact brought new models of professional development that rely primarily on electronic communication. These models dispense with reliance on videotaped lectures and are instead grounded in new distance learning tools and based on research on how people learn. This NASA funded project provides an opportunity to develop an online PD model and deliver it to K-12 teachers and by extension to their students all over the United States.

Electronic Professional development (ePDN) courses are designed to model best practices in teacher PD by incorporating inquiry-based learning and promoting the types of active interaction and reflection by participants that normally occur in effective face-to-face professional development sessions. The Technology Integration Certificate consists of four courses designed to help teachers become more comfortable with technology tools and integrate them in their classrooms. The courses include an introduction to podcasting for novices, the creation and implementation of vodcasts for more advanced users, on-line teaching for educators seeking to develop electronic versions of their classroom lessons, and $3 \mathrm{~d}$ visualization, the fourth course developed to introduce the engineering design process in a global context. The first course within the Technology Integration Certificate, Engage and Educate - Podcasts In The Classroom, provides participants with examples of how podcasts can be integrated in classroom lessons to engage students in learning about STEM disciplines. During the course, the pros and cons of podcasts are examined and participants are introduced to the tools and techniques for creating podcasts. Through an on-line blog, participants review podcasts currently available through iTunes and other interfaces and share their views on each podcast's potential usefulness in a classroom setting. For a final project, participants create their own podcasts, first designing them using storyboards and then creating an mp3 file that is shared through an RSS feed.

In this study, we described the ePDN Podcast course and its impact on teachers' professional development. In addition, upon completion of the podcast course, we investigated the longitudinal effects of the course by exploring how podcasts were used in the classroom setting. The principle research method employed in this study is to develop aggregate narratives. The narratives describe the effectiveness of the podcast course from the perspective of each course participant.

\section{Background}

Each ePDN course consists of a combination of synchronous and asynchronous components, and entails 52 hours of work time by each participant, generally over the course of 14 weeks. Each course is broken up into five 10-hour stand-alone modules, with a 2-hour 
introductory module that provides information about the types of virtual learning tools that will be featured in the course and how to use them. Teachers who successfully complete 52 hours of professional development, either from one course or as a combination of modules chosen from different courses, receive Continuing Education Credits and a non-credit certificate from Georgia Tech that can be used by school systems to award local professional learning units (PLU) or credits. The Learning Management System (LMS) used by Georgia Tech is a program called Sakai. Sakai is an open source LMS. The Georgia Tech version of Sakai is known as T-Square.

The ePDN courses were created using the ASSURE model of Instructional Design ${ }^{2}$. The ASSURE model is based on Gagne's Nine Events of Instruction ${ }^{3}$. Gagne believes that there are nine events or processes that need to occur for effective learning to take place. The nine events are: 1. Gain attention, 2. Inform learners of objectives, 3. Stimulate recall of prior learning, 4. Present the content, 5. Provide guidance for learners, 6. Elicit performance, 7. Provide feedback, 8. Assess performance, and 9. Enhance retention and transfer. These nine events provide the basis for the design of the instruction model and for choosing the right media. ${ }^{4}$ The ASSURE Model emphasizes teaching with different styles and the active participation of the students in the learning process. It adapts Gagne's nine events of instruction into six categories as follows ${ }^{5}$ :

- Analyze learners: Understand the target audience. This can be achieved by analyzing demographic information, entry level competencies and learning styles.

- State objectives: Once understanding of the target audience is achieved, lesson objectives must be formulated.

- Select instructional methods, media and materials: Once objectives are formulated, instructional methods, media, and material that are relevant to the learning outcomes must be selected.

- Utilize media and materials: Instructors must preview, prepare, and use the media and materials in order to provide an effective learning experience.

- Require learner participation: Students should be actively involved in the learning process. This could include activities, group work, projects, discussions, etc.

- Evaluate and revise: This is the most important step. At the end of each lesson, instructors should reflect on the lesson, the objectives, the learning outcome and the assessment to determine if the lesson was effective. Instructors should also obtain feedback from the students. Finally, at the end of the course, instructors should evaluate the entire course for the effectiveness of the teaching and learning process. Based on the reflection, feedback, and evaluation, the course should be revised to better meet the needs of the students and to ensure the effectiveness of the lessons.

In addition to the ASSURE model, the Quality Matter (QM) rubric was used as an evaluation tool and guidance for the instructor to design the delivery of the curriculum. The QM rubric consists of 40 key online course elements distributed across eight broad standards shown to impact student learning. The most critical course components related to those standards are: "Learning Objectives," "Assessment and Measurement," "Resources and Materials," "Learner Engagement," and "Course Technology." These measures are designed to align and work together, ensuring that students achieve the desired learning outcomes. The main benefit of using 
the QM rubric is in assisting course designers and instructors in effectuating clearer alignment of course/unit learning objectives with assessment materials and instruments, as well as making thoughtful decisions as to where to place such materials in the course schedule and how to replace course materials and instruments for future course revisions. Additionally, the QM rubric provides a clear set of guidelines for instructors.

\section{The ePDN Model}

The ePDN courses are designed to model best practices in teacher PD by incorporating inquiry-based learning and by promoting the types of active interaction and reflection by participants that normally occur in effective face-to-face professional development sessions. These courses, which are asynchronous but are offered over a set period of time and require weekly participation, incorporate constructivist pedagogy (project-based learning, student centered learning, and collaborative learning environments) and offer the types of support that are characteristic of actual face-to-face activities ${ }^{6}$. For example, participants are required to work collaboratively, contributing various perspectives through wikis, chat rooms and forum discussion boards. Participants also share work electronically, providing each other with useful ideas about how to incorporate new materials into the actual classroom. Instructors interact

\section{Course Outline}

Week 1 - What Are Podcasts

Module 1 - Overview of podcasts

- What Are They?

- How Are They Currently Used In Education?

- Reflection and Sharing on Readings

Module 2 - Working with Podcatchers

- Downloading, Installing and Navigating in iTunes

Module 3 - Collaborative Activity

Week 2 - Podcasts

Module 1 - NASA Podcasts

- Podcast Rubrics

Module 2 - Storyboards

- Storyboard Template

Module 3 - Collaborative Activity

Week 3 - Audio Editing

Module 1 - Audio Editing

- Downloading and Installing Audacity and LAME

Module 2 - Working with the Tools

- Audacity Tutorials

Module 3 - Collaborative Activity

Week 4 - Creating a Podcast

Module 1 - Putting It All Together

- Produce a podcast using Storyboard and Rubrics

- Upload Podcast as MP3 file

- Share podcast through RSS feed and iTunes

Module 2 - Collaborative Activity frequently with participants through discussion forums, blogs, and podcasts, reflecting on the work completed during that week.

Well developed online learning requires more than just a simple shift from one medium to another. Rather than making online courses an extension of and/or substitute for traditional classes, designers should perform a large scale online simulation in which a single task or project becomes the focus of the learning environment. Another innovative model for online courses that takes advantage of the pedagogical benefits of online learning and advances in situated learning theory is virtual "knowledge rooms" where learners are provided the collaborative space for deep learning ${ }^{7}$. The ePDN model of online 
instructional activities, tasks, and tools aims to engage course participants at a high level of learning from a constructivist perspective. The course tools, multimedia presentations, text, and narration is designed to help participants take control of their learning and monitor their own progress towards achieving goals. The main approach is to encourage an engaging learning environment based on constructivist principals and problem-based learning. Student engagement is an important component in online learning, and the research literature documenting the importance of participant interaction in online learning is extensive.

The Podcast course was organized into weekly themes and topics. The website for the course included a syllabus, assignments, weekly learning goals and questions, supplementary course materials, and related links. These materials were always available and served as the organizational anchors for the course. Each topic was organized for an asynchronous discussion on an electronic discussion board during a specific week and was based on weekly assignments. Collaboration is an integral part of NASA ePDN courses. To foster collaboration, participants were asked to post biographical information on the discussion boards and were required to respond and interact with each other within the groups. The use of students as facilitators was designed to encourage them to be contributors to, and not simply passive participants in, learning activities. Students were encouraged to contribute to the discussion by asking questions of other students or the instructor. Throughout the course, students were encouraged to engage in lively discussion and create a sense of online community.



Figure 1 - Podcast Rubric

\section{Course Content}

The course was designed for teachers with very little to no knowledge about podcasts. That is, they had neither downloaded or used podcasts in their classrooms, produced one for their students, parents, or peers, nor had they instructed their students in the creation of podcasts. They also had little if any knowledge working with podcatchers such as iTunes or Juice. So the course began with introductory readings about podcasts and how they are currently being used in education, both within the K-12 community as well as higher ed. After establishing the benefits and hindrances to podcasting, the next step was to introduce participants to the relevant media technologies. For many, using an application such as iTunes to subscribe to, download, organize, and listen to podcast episodes was a new experience. It was also the first stumbling block many encountered as iTunes was often blocked behind firewalls within school networks, 
providing students with a useful and practical problem solving experience in itself.

A list of podcasts suitable for use in K-12 classrooms was provided to participants, and they were asked to share their thoughts about the episodes and then contribute to the list with other podcasts they had discovered. Through this sharing and discovery process, teachers found numerous resources along with guidance from classmates on strategies for including podcasts in lesson plans and class assignments.

Focusing more specifically on NASA content suitable in a STEM classroom, teachers were provided with a rubric (see figure 1) to critique a series of five podcasts produced by a variety of NASA programs. This rubric would also serve as a tool for creating their own episodes and to eventually assess student produced podcasts. The process of reviewing professionally developed podcast episodes, such as those from NASA, gave them examples of what elements made for memorable podcasts in contrast to those which were quickly forgotten.

Having gone through the steps of being podcast consumers, the next step for the students was the planning stage for becoming producers. A storyboard template was provided along with a process to help students select a topic, plan the message to relate about the topic (keeping it

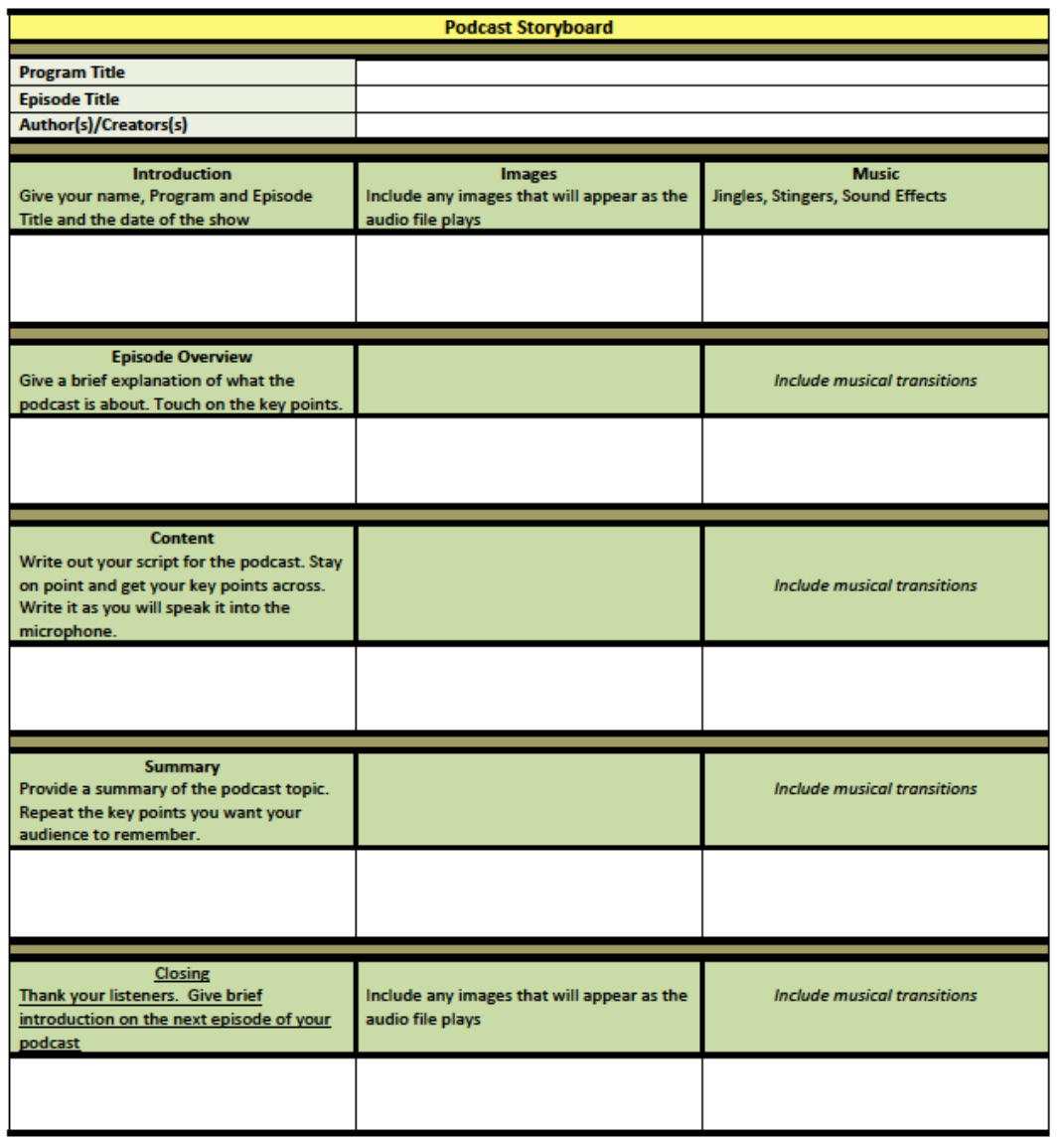

Figure 2 - Podcast Storyboard Template short, concise, and focused), and include elements to create an engaging podcast episode. Prior to working with any audio editing software, each participant had to submit their storyboard, which delineated with some level of detail each aspect of the podcast episode, including introductory music, script, transitions, closing credits and music. The storyboard is a critical component of integrating this new technology in the classroom, as it is the exercise that provides an assessment tool for educators and creates a learning process for students in which there is repetition and reexamination of ideas and concepts on a given topic. The next step deals directly with the technology, creating a mobile learning, "anytime, anywhere" experience through a podcast. Audacity is the cross-platform (Mac and PC) audio editing software tool used to generate the 
audio files that are formatted into MP3 files for playback on computers, MP3 players, smartphones and other mobile devices, such as iPads. In a series of tutorials, participants were instructed in the use of Audacity's tools for recording their voices, adding music as introduction or background, inserting other audio clips, and including any number of effects and filters to create unique styles and presentations. Upon mastering Audacity, each participant produced a podcast episode based upon their previously created storyboard. The podcasts were shared within the class through the RSS feed address and made available through iTunes.

The course provided participants who were new to podcasts with a framework for using this media not just as an exercise to engage students, and students with diverse learning styles, but as a means to communicate with parents, peers, and the community. Throughout the course, participants' discussions in the forums, blogs, and chat room, ranged from the many ways podcasts could be used in various disciplines, to funding opportunities for acquiring technology, and methods for dealing with other concerns such as IT and firewall issues, copyright infringement, and privacy concerns.

Student produced podcasts varied dramatically as each was geared to situations or responded to a need within their classroom. As examples, one podcast dealt with lab safety and was produced as a tool to introduce the topic before anyone stepped into the lab. Another student produced podcast similarly introduced the scientific process. Other podcasts dealt with earth science issues, robotics, orbital mechanics, renewable energy solutions, and the integration of other technologies such as e-publishing. Some podcasts dealt with pragmatic issues that educators face each school year such as informing parents of homework policies. Podcasts became tools for participants to use not just as a new technique to have their students attempt but also as a way to efficiently communicate information to them or their parents.

\section{Methods}

\section{Sample}

123 applications were received for the Podcast course. The registration phase was open to all applicants, and 40 applicants were able to complete the registration steps by the deadline. Of 40 students, 26 successfully completed the course, meaning they completed at least $75 \%$ of the course requirements. Demographically, $83 \%$ of the participants were Caucasian, $8 \%$ were Hispanic, and $5 \%$ were African American. In addition, 26 participants were female and 14 male.

\section{Data Collection Methods}

This study focused on in-depth understandings of participants' online collaboration and course satisfaction using case study methodology. According to Merriam (2001), a case study is "an intensive, detailed description and analysis of a particular individual, group, or event". The purpose of using descriptive case studies in the instant context is to present basic information about areas of education where little research has been conducted ${ }^{8}$. The case study is the most appropriate qualitative method for this study because each case will be bounded by an ePDN course. 
Ruhu and Zumbo's "unfolding" model ${ }^{9}$ was used as the theoretical framework to collect data for the evaluation purpose. According to the authors, the following kinds of data need to be collected to accurately present scientific evidence:

- Scientific evidence:

- Surveys/interviews/focus groups/online ethnographies to measure learner satisfaction with course components

- Tutor

- Online discussion group

- Course Package

- Course Materials

- Checklist and rubrics to measure the environmental quality

- QM Rubric

- Outcomes

- Completion and retention rates

- Students feedback

- Data/Statistics to track learner progress

The evaluation research design was formative in nature. It emphasized multiple data collection methods and exploratory analyses. The key evaluation question was: "To what extent were course participants satisfied with the course?" A variety of data sources were used in this study, including participants' weekly feedback reports, forum and wiki discussions, end-ofcourse evaluations, and the course statistics provided through the Sakai course management system. Data on actual participation in online discussions were collected throughout the course. Students also completed a course evaluation survey at the end of the course which asked a series of questions addressing their overall experiences, especially as related to course satisfaction, interaction with the instructor and the technology used.

From an evaluation perspective, the evaluation team monitored whether the goals of the Podcast course were being achieved by observing the following: a) student satisfaction with the Podcast courses; b) the value added to the educational experiences of teachers receiving professional development. Furthermore, the effectiveness of the Podcast course was assessed by providing formative guidance as to course implementation, educational components, and educational partnerships relationships.

At this point, the qualitative analysis started with breaking the data into interpretive activities which involved categorization of small, discrete coded units. Although the intent was to minimize bias and erroneous findings, it is important to note the caveat that this study is designed to describe the course participants' experience-- not to make generalizations about podcast use or teacher professional development.

\section{Course Evaluation Results}

The participant background survey was administered at the beginning of the course, and was completed by 36 participants. The participants were asked about their expectations from 
online learning. "The navigation of the course website and the workload" were described as the two most important components in online learning. Participants were asked again at the end of course evaluation to see if their expectations were met. $91.3 \%$ of the students indicated that the instructor provided timely feedback, and $75 \%$ of participants were pleased with the forum discussions. In addition, $96 \%$ of participants agreed or strongly agreed (only one person reported neutral) that the course met their expectations.

The participants were also asked about their reasons for taking the NASA ePDN Podcast course. The following was reported:

- A majority of participants $(90 \%)$ reported that they want to utilize NASA materials in their classroom.

- $90 \%$ of teachers believed that the Podcast course will help them to teach academic content, knowledge and skills more effectively.

- $85 \%$ indicated that they do not know how to create Podcast, use iTunes and have no prior experience using these kind of technology in their classroom. Additionally, they reported that this is a great professional development opportunity for them since their schools or districts have hard time providing trainings about technology integration into the classroom.

- Participants' general expectation was that the course would provide them with an opportunity to learn new ways to teach a variety of topics.

Participants also agreed that the instructor clearly communicated important due dates/time frames for learning activities, and how to participate in course learning activities. In addition, a majority of participants agreed or strongly agreed that overall effectiveness of the course and the instructor was very good.

$96 \%$ of the teacher participants reported that the course increased their knowledge about NASA curriculum materials and the use of Podcasts. Feedback from participants in the content course indicates that participants were generally satisfied with the course. Participants found the course challenging, though not over their heads, and they appreciated the opportunity for online chats with other participants and/or the instructor. All of the participants of the survey either strongly agreed or agreed that the lectures contributed to their learning (85\% and $15 \%$ respectively). Additionally, all of the participants agreed that they could apply want they learned, that the work load was appropriate and that the course activities piqued their curiosity. Participants reported that the workload was more than they expected in the last week of the course. However, the participants were very pleased about sharing their final podcast projects on the course online discussion tool.

"It is great to see others podcast, I am happy that I am ending this course with a good quality podcast, which I plan to use in my classroom" To conclude, the majority of the comments/suggestions from the survey were positive and most of the respondents expressed a desire to take another technology course (the ePDN Vodcast course). Additionally, participants reported that they are planning to implement the course materials and use NASA materials in their classrooms, and are willing to report about their experience. The only downside to the course seemed to be time constraints. The participants asked for extra time to complete the last assignment, and several of them used an extra week to complete the course. 


\section{Collaboration and Forum Discussions}

Navigation of the online tools was generally reported as good. While some students stated that the collaboration tools were useful, others reported that there were too many tools for collaboration and it was hard to keep track of all them. The Chat Room, which is for comments and questions about the course, was used as the main place for communication. The Forum was used as a place for open discussion and questions, where participants could post questions to which the instructor and/or other participants in the class could respond and which could be organized in related threads instead of a collection of random disconnected snippets, which is what the Chat Room generally tended to become. Additionally, OpenStudy was offered as an optional tool for collaboration outside of T-square. The use of OpenStudy was moderate. It was also observed that participants did not continue to use OpenStudy after completing the course. Additionally, NASA Talk site was used as a collaboration tool. NASA Neon was also introduced to the participants to serve as a platform connecting with other educators based on areas of expertise, interests, and needs, developing effective collaborations and exploring teaching, learning and professional development resources. The use of these sites were also moderate. Most of the feedback and/or comments provided about collaboration sites were positive.

Participants also explored the NASA Do It Yourself Podcasts, which provides a resource for educators who are interested in becoming more familiar with podcasting. The Do It Yourself Podcasts provide a set of audio and video clips along with photos and information about a spacerelated topics. This resource was praised by course participants.

The discussion forum for the course was broken up into course questions, discussions and course readings. Over the course of 4 weeks those who participated in the online class were asked to respond to questions/assignments posted online in addition to providing reflections, comments, and/or suggestions. These discussions offered a platform for participants to voice their concerns and important questions about using and creating Podcasts in the classroom. The students were also resourceful in adding additional insights from personal experience, as well as websites/links to articles and videos that they believed would be helpful to their classmates.

Teachers agreed that "time" is the greatest obstacle when introducing podcasting into the curriculum because it requires new learning on the part of both teacher and students. However, they also stated that podcasting is a great vehicle for motivating and engaging students to delve deeper in to the academic content. As one teacher stated:

"Anytime you involve students in their own learning they become more engaged but having them understand the value of why they are creating the podcast and for what audience can make all the difference in the personal level they choose to become engaged."

Another teacher said "That aspect of podcasting intrigues me the most because it addresses one of the biggest problems we face in our school... getting kids engaged in the learning process. I think because of that factor, podcasts will not be a fad and will become more widely used in schools."

Teachers also discussed the ways of implementing podcast use in the classroom. A majority of them indicated that they would shorten "the written assignments" and have their 
students create podcasts instead of written assignments. They also agreed that they can use the podcast to deliver the content. According to teachers, the basic advantage of podcasting in education is the portability and convenience of listening resources which are available anytime and anywhere. Podcasting has great potential for their students since most of their students already own mobile players. Hence, podcasting makes the course content more attractive to students.

In addition, when teacher participants were asked to describe the impact of Podcast course on their professional development, the majority of respondents mentioned the quality of the course materials (e.g.: storyboard, podcast rubric). The support from the course instructor emerged as the most important component of program effectiveness. Participants stated the appreciation of instructor-teacher interactions and the value of these interactions in becoming a better teacher.

"Excellent class. I learn so much from the instructor as well as the other students in the class. It was a wonderful learning curve with techniques I can use in my classroom."

"This course was so packed with valuable information not only on directing us to NASA content but how to use tools to effectively create and publish podcasts in our own classrooms. I thought I had a pretty good idea of what and how to do podcasting until I took this course. There was so much more that I learned and now I can share with my students as well as the teachers I work with."

According to the teachers, the course was effective in preparing them with respect to their teaching and the skills they would need to use the podcast in the classroom. In particular, they recognized that the course was effective because it utilized the accumulated wisdom of their professional community, rather than trying to re-invent approaches to teaching and learning individually. Participants felt that they would become better teachers with a better understanding of technology integration in the classroom. Teachers described the course as an "excellent experience."

Course evaluation results also showed that the teachers gained a deeper understanding of the use of Podcasts in the classroom. As one teacher expressed, "After this class, I now have a better idea how to incorporate technology in my curriculum. I enjoy learning about the online NASA materials and will use them in my teachings. I think using these materials can make a marked difference in the students when technology is used in the classroom. As we are advancing our students can explore and learn about a ton of things using the technology. After taking this course, I will be able to impart this knowledge down to my students." Another explained, "As a professional development trainer for $K-12$ teachers this is an invaluable course that will allow me to show other educators how to integrate NASA content not only into their classrooms but how to actually use existing NASA content and empower the teachers and their students to create podcasts that will enhance technology, language arts, science, and math skills through hands-on doing. "

\section{Follow Up Survey Results}

A follow up survey was sent to the 26 participants who successfully completed the course through an electronic survey software program called Survey Gizmo. The response rate within a few weeks of the initial e-mailing was $50 \%$. The second follow up reminder was sent after two 
weeks of the initial e-mailing. The second reminder increased the response rate to $60 \%$. Next, we sent out weekly reminders to all the participants that did not respond to the electronic survey. Leeuw, Hox, and Dillman (2008) ${ }^{10}$ suggest that 10 days to 2 weeks is reasonable interval between survey reminders (either through mail or e-mail). At the end of one month, the response rate was $73 \%$ (19 participants).

The survey results showed that $68 \%$ of the survey respondents were able utilize Podcasts in their classroom. Mostly teachers used podcasting to deliver course content. For example, one teacher created podcasts for students to listen and practice Spanish pronunciation. Another teacher used it to emphasize critical information in science class. Teachers reported that podcasts helped them to communicate with their students outside of the classroom and enabled direct interaction with students, which go beyond the temporal and spatial limitations of conventional face to face education. Additionally, teachers felt that podcasting offers a timely and expedient delivery method for a wide range of teaching resources especially when combined with iconic and ubiquitous MP3 devices such as Apple's iPod. They believe the culture of learning and its integration into students' daily lives is changing, and using podcasts helped them to engage and motivate their students in the classroom.

Another positive finding emerged from the follow up survey was dissemination of the course materials in the schools. $95 \%$ of the teachers shared the course materials with other teachers. Several teachers indicated that they conducted workshops for fellow teachers about how to create and use podcasts. One teacher used the podcast to provide audio feedback on assignments instead of written comments. This was highly valued by the students and was considered a more effective method of feedback delivery than receiving written notes, both in terms of comprehension and aiding practical improvements in their work.

Teachers generally extolled the benefits of using podcasting. As one teacher said, "the use of podcasting has given me the opportunity to direct my students to listen, investigate, and analyze the data more thoroughly. Also, my students loved to have the resources available from the technology to listen multiple times." Teachers clearly indicated that learning how to podcast benefited their teaching. The following table summarizes some of the important findings from the survey.

\begin{tabular}{|c|c|c|c|c|}
\hline & $\begin{array}{l}\text { Strongly } \\
\text { Agree }\end{array}$ & Agree & Neutral & Disagree \\
\hline $\begin{array}{l}\text { After participating in a ePDN Podcast course, I } \\
\text { am confident in my ability to apply the } \\
\text { knowledge and/or skills learned }\end{array}$ & $53 \%$ & $42 \%$ & $5 \%$ & 0 \\
\hline I have used the materials in my classroom. & $68 \%$ & 0 & $32 \%$ & 0 \\
\hline $\begin{array}{l}\text { I am sharing these materials with other teachers, } \\
\text { formally or informally. }\end{array}$ & $95 \%$ & 0 & 0 & $5 \%$ \\
\hline $\begin{array}{l}\text { Based on course experience, I have changed my } \\
\text { teaching activities. }\end{array}$ & $95 \%$ & 0 & 0 & $5 \%$ \\
\hline
\end{tabular}




\section{Conclusion}

This paper described the NASA Podcast course and its impact on teachers' professional development. It has also explored the idea that the use of podcasts is an effective method for delivering content. Furthermore, there is a great need for teacher professional development for technology integration in the classroom. Today's students are increasingly more technologically "savvy," and K-12 teachers need to be encouraged to use more instructional technologies. Podcasting may be a vital strategy in engaging and motivating students in the classroom. Teacher participants' responses about the Podcast course were positive and constructive as they addressed the importance of learning new technologies. They also indicated that their new skills in implementing technology enhanced their professional development.

The results of this study showed that this course was successful in meeting K-12 teachers' needs. Furthermore, instructional technology such as podcasting provides excellent tools for future teaching and learning and for building meaningful bridges between instructors and students. The results of this study demonstrate the importance of professional development for K-12 teachers in the effective implementation of instructional technologies such as podcasts.

\section{References}

${ }^{1}$ Brock, D. (2009). Professional development changes classrooms. Learning and Leading with Technology, 37(2), p. 10

${ }^{2}$ Heinich R., Molenda, M., Russell, J, \& Smaldino, S. (1999). Instructional Media and Technologies for Learning. New Jersey: Prentice Hall

${ }^{3}$ Gagne, R. (1985). The Conditions of Learning (4th ed.). New York: Holt, Rinehart \& Winston.

${ }^{4}$ Gagne, R., Briggs, L. \& Wager, W. (1992). Principles of Instructional Design (4th Ed.). Fort Worth, TX: HBJ College Publishers

${ }^{5}$ Academy of Teaching Excellence. (2002). Course construction: Assure. Retrieved August 15, 2008, from www.mscd.edu/ act2/courseconstruct/assure.html.

${ }^{6}$ Barab, S.A., Squire, K.D., \& Dueber, W. (2000). A co-evolutionary model for supporting the emergence of authenticity. Educational Technology Research and Development, 48(2), 37-62.

${ }^{7}$ Herrington, J., Oliver, R. and Reeves, T. C. (2003). Patterns of engagement in authentic online learning environments. Australian Journal of Educational Technology, 19(1), 59-71.

${ }^{8}$ Merriam, S. B. (2001). Qualitative research and case study applications in education: Revised and expanded from case study research in education. San Francisco: Jossey-Bass Publishers.

${ }^{9}$ Ruhe, V. and Zumbo, B. (2009) Evaluation in Distance Education and e-Learning London/New York: Guildford Press

${ }^{10}$ D. de Leeuw, Joop J. Hox, \& Don. A. Dillman (2008). International Handbook of Survey Methodology. New York, NY: Lawrance Erlbaum Associates. 